\title{
Brain injury markers: where are we?
}

\author{
Stefania Mondello ${ }^{1 *}$ and Frank C. Tortella ${ }^{2}$ \\ ${ }^{1}$ Department of Neurosciences, University of Messina, Messina, Italy \\ ${ }^{2}$ Brain Trauma Neuroprotection and Neurorestoration Branch, Walter Reed Army Institute of Research, Silver Spring, MA, USA \\ ${ }^{*}$ Correspondence: stm_mondello@hotmail.com \\ Edited and reviewed by: \\ Mårten Risling, Karolinska Institutet, Sweden
}

Keywords: biomarker, brain injury, traumatic brain injury, discovery, clinical practice

Traumatic brain injury (TBI), a growing public health problem, appears to result not only from major andprimary injury but also from a complex interplay among inflammatory, biochemical, and neurohormonal changes, as well as genetic components acting on brain tissue. As a result, characterization and classification of TBI requires multidimensional approaches that are able to encompass the diverse and highly complex clinical picture of TBI across the continuum of severities and broad spectrum of pathobiological processes. Emerging evidence suggests that an increasing number of biologic substances, commonly referred to in today's vernacular as biomarkers, can provide unprecedented opportunities for detecting and classifying injury, and identifying pathophysiologic mechanisms potentially leading to more effective targeted therapies.

In this Research Topic, we include comprehensive reviews of the current literature on this topic ranging from proteomics techniques applied for the first time to central nervous system (CNS) biomarker discovery (1) to potential clinical applications of existing biomarkers of brain injury in specific settings such as ICU, pediatric TBI (2), and the military-relevant battlefield casualty (3). In particular, to address the unique circumstances and consequences of sustaining a TBI in combat and the demand for specific practices of management and care of soldiers, presentations $(3,4)$ have been included from outstanding researchers of the Combat Casualty Care Research Program (CCCRP) for Brain Trauma and Neuroprotection, a program specifically focused on developing neuroprotective and neurorestorative strategies for militaryrelevant TBI. We have also added a chapter on blast TBI to emphasize the potential problem of TBI following exposure to blast (5). Finally, we expanded discussions to explore the potential of brain damage biomarkers as tools for predicting long-term consequences of TBI (6) and to outline their roles in other CNS diseases such as neurodegeneration (Parkinson's disease) (7), subarachnoid hemorrhage (8), and hypoxic ischemic encephalopathy $(9,10)$.

We have strived to assemble a multidisciplinary group of internationally recognized researchers and clinicians highly relevant to this research domain (11-13). As the translation of brain damage biomarkers has already transformed from research tools to being aids in clinical decision-making, this Research Topic will be evolutionary reading for neurotrauma scientists and clinicians interested in the potential of a simple biofluid-based diagnostic test to refine the clinical characterization of TBI offering more accurate disease phenotyping. Such improved molecular characterization integrated with traditional approaches, including clinical examination and structural and functional neuroimaging, will allow the field to develop improved clinical practice guidelines and tailor therapeutic interventions to the patient's individual pathophysiology, thereby leading to effective management and improved patient outcome.

This Research Topic would not have been possible without the support and help of many people. First, we thank the chapter authors for devoting their time and effort to produce valuable contributions that provide comprehensive frameworks and critical insights. We also thank the members of the editorial board for their dedicated assistance and for providing informed perspectives on the chapters. Last, and most important, we thank all patients with TBI and their families for their invaluable contributions. To improve their outcome and quality of life represents our ultimate goal and our greatest source of inspiration to foster knowledge in this critical research area.

\section{AUTHOR NOTE}

Material has been reviewed by the Walter Reed Army Institute of Research. There is no objection to its presentation and/or publication. The opinions or assertions contained herein are the private views of the authors, and are not to be construed as official, or as reflecting true views of Department of the Army or Department of Defense.

\section{REFERENCES}

1. Guingab-Cagmat JD, Cagmat EB, Hayes RL, Anagli J. Integration of proteomics, bioinformatics, and systems biology in traumatic brain injury biomarker discovery. Front Neurol (2013) 4:61. doi:10.3389/fneur.2013. 00061

2. Kochanek PM, Berger RP, Fink EL, Au AK, Bayir H, Bell MJ, et al. The potential for bio-mediators and biomarkers in pediatric traumatic brain injury and neurocritical care. Front Neurol (2013) 4:40. doi:10.3389/fneur.2013. 00040

3. Schmid KE, Tortella FC. The diagnosis of traumatic brain injury on the battlefield. Front Neurol (2012) 3:90.doi:10.3389/Fneur.2012.00090

4. Shear DA, Tortella FC. A military-centered approach to neuroprotection for traumatic brain injury. Front Neurol (2013) 4:73. doi:10.3389/fneur.2013. 00073

5. Kobeissy F, Mondello S, Tumer N, Toklu HZ, Whidden MA, Kirichenko N, et al. Assessing neuro-systemic \& behavioral components in the pathophysiology of blast-related brain injury. Front Neurol (2013) 4:186. doi:10.3389/fneur.2013. 00186

6. Turner RC, Lucke-Wold BP, Robson MJ, Omalu BI, Petraglia AL, Bailes JE. Repetitive traumatic brain injury and development of chronic traumatic encephalopathy: a potential role for biomarkers in diagnosis, prognosis, and treatment? Front Neurol (2012) 3:186.doi:10.3389/fneur.2012.00186

7. Constantinescu R, Mondello S. Cerebrospinal fluid biomarker candidates for parkinsonian disorders. Front Neurol (2013) 3:187. doi:10.3389/fneur.2012. 00187. 
8. Amiri M, Astrand R, Romner B. Can S100B predict cerebral vasospasms in patients suffering from subarachnoid hemorrhage? Front Neurol (2013) 4:65. doi:10.3389/fneur.2013.00065

9. Douglas-Escobar M, Weiss MD. Biomarkers of brain injury in the premature infant. Front Neurol (2012) 3:185. doi:10.3389/fneur.2012.00185

10. Douglas-Escobar M, Weiss MD. Biomarkers of hypoxic-ischemic encephalopathy in newborns. Front Neurol (2012) 3:144. doi:10.3389/fneur.2012.00144

11. Maas AI. Prefactory comments: promise and enigma of biomarkers for brain injury. Front Neurol (2012) 3:173. doi:10.3389/fneur.2012.00173

12. Woodcock T, Morganti-Kossmann MC. The role of markers of inflammation in traumatic brain injury. Front Neurol (2013) 4:18. doi:10.3389/fneur.2013.00018

13. Tsitsopoulos PP, Marklund N. Amyloid-beta peptides and tau protein as biomarkers in cerebrospinal and interstitial fluid following traumatic brain injury: a review of experimental and clinical studies. Front Neurol (2013) 4:79. doi:10.3389/fneur.2013.00079
Conflict of Interest Statement: The authors declare that the research was conducted in the absence of any commercial or financial relationships that could be construed as a potential conflict of interest.

Received: 17 July 2014; accepted: 21 July 2014; published online: 04 August 2014. Citation: Mondello S and Tortella FC (2014) Brain injury markers: where are we? Front. Neurol. 5:145. doi: 10.3389/fneur.2014.00145

This article was submitted to Neurotrauma, a section of the journal Frontiers in Neurology.

Copyright (C) 2014 Mondello and Tortella. This is an open-access article distributed under the terms of the Creative Commons Attribution License (CC BY). The use, distribution or reproduction in other forums is permitted, provided the original author(s) or licensor are credited and that the original publication in this journal is cited, in accordance with accepted academic practice. No use, distribution or reproduction is permitted which does not comply with these terms. 